\title{
Strengthening Free Healthcare in Rural Nepal
}

\author{
Bibhusan Basnet,' Bikash Gauchan, 'Rishav Shrestha, 'Ashma Baruwal,, Gregory Karcles, 'Zach Silver \\ ' Bayalpata Hospital, Ridikot- 2, Achham, Nepal.
}

\section{ABSTRACT}

Nepal, a mountainous country in South East Asia, still lags in increasing access to healthcare and reducing health inequity. Possible Non Government Organization based in Achham, Nepal, which is a sister organization of Possible International Non Government Organization based in New York, USA recognized the increasing health needs in the far western rural hilly parts of Nepal, where extreme poverty and illiteracy was creating a vulnerable picture especially in Achham. Possible (previously named Nyaya Health) started to operate Bayalpata Hospital in 2009 after completing more than one year of free health services in Sanfe-Bagar, Achham, in partnership with the Nepalese Ministry of Health and Population. It supports the idea that free health service has its own challenges but a public-private partnership can thrive while promote equity in health services.

Keywords: achham; free health care; nepal; nyaya health; possible.

\section{INTRODUCTION}

Over the last several years, Nepal has made an effort to expand healthcare access by reducing health inequity. In January 2009 the government implemented the "New Nepal, Healthy Nepal" initiative, which has provided Nepalese with free access to District Hospitals (DHs) and Primary Health Care Centers (PHCs). ${ }^{1}$ These hospitals and centers distribute medicine and provide patients with basic emergency and outpatient services. The private sector has made strides to promote health equity since the early 1990s. Most of these efforts, however, have focused predominantly on urban communities. $^{2}$

Despite these progressive policies to "bring health to all", poor access to healthcare remains a serious problem among rural and marginalized communities in Nepal. Achham, a district in Far West Nepal, is a marked example of the inequity embracing Nepal's healthcare system. As one of the worst hit districts due to chronic poverty, difficult terrain, and government neglect, Achham suffered more in the immediate aftermath of the decade long insurgency. The health infrastructure, which was already in tatters, was completely destroyed. At the time Possible (previously known as Nyaya Health) began providing free health services at Bayalpata in 2009, there were no doctors in Achham and the nearest operating room was 10 hours away by bus. ${ }^{3}$ The purpose of Possible was to provide healthcare services, also advocate for and contribute to the development of a stronger healthcare infrastructure.

Correspondence: Dr. Bibhusan Basnet, Bayalpata Hospital, Ridikot- 2, Achham, Nepal. Email: bibhusan117@gmail.com, Phone No: $+9779842060711$ 
Possible was founded upon the idea that healthcare should be universally accessible. In this vein, Possible partnered with the Government of Nepal (GoN) to provide curative and public health services.Possible revived Sanfe-Bagar Health Clinic in 2009. The primary objective was to provide free basic health care services to target population. ${ }^{4}$ By doing so,Possible envisioned that equity in healthcare would be achieved in Achham. Due to high patient flow in the Sanfe-Bagar Health Clinic within the first two years, a district level care center was set up in the abandoned Bayalpata Hospital in Achham. This was the base for providing curative health services. As time passed, health inequity present in the Achhami community needed to be addressed better. A community health program was therefore devised in 2010. This program monitors Female community health volunteers (FCHVs) of the Nepal Government, trains them and redeploys them as community health workers to serve both as healthcare providers and as social advocates for change in their communities.

\section{Care Delivery Model}

Bayalpata Hospital has been upgraded to (and continuously being upgraded to) a modern facility delivering evidence-based and high-quality health care services: curative, preventive and rehabilitative. The primary health services are continuously being expanded to various healthcare services that are enlisted in Table 1.

\section{Table 1. Services Available through Possible}

1. Outpatient and inpatient service

2. Emergency service

3. Laboratory service

4. X-ray service

5. Ultrasound service

6. Pharmacy

7. Maternal Health program providing Basic Emergency Obstetrics Care (BEOC)

8. Prevention of mother to Child Transmission program (PMTCT) program

9. Comprehensive Abortion Care (CAC) service

10. Anti-Retro viral Therapy (ART) program

11. Directly Observed Treatment Short Course (DOTS) for TB

12. Community Based Management of Acute Malnutrition (CMAM) Program

13. Mental Health Program

14. Blood Bank service

15. Specialists Health Camp service

16. Community health program
All the services provided by the hospital including the outpatient, inpatient services, lab services, drugs are supplied free of cost. The services are available 24/7 through a team of clinicians and community health workers. By implementing a scalable model of health care delivery, Possible has been delivering free community based health care services in Rural Nepal.

\section{Curative care delivery}

The hospital has provided both inpatient and outpatient services since its inception. The patient flow is about 88 outpatient visits per day. By 2012, Possible's Bayalpata Hospital consists of 58 hospital based clinical and administrative staffs. Emergency services with ambulances were started in 2009 after shifting from the Sanfe-Bagar Clinic to Bayalpata Hospital. Basic Laboratory and Pharmacy services have been available since 2009. The inventory was increased to 465 different medications by 2011 . There were 5 beds when the hospital began. Currently, it has been expanded to 15 inpatient beds including two isolation beds.

The Obstetrics and Gynecology program was started in 2010 along with Pediatrics. Comprehensive Abortion Care Services were started concomitantly. Pediatric intensive care unit (PICU) began in 2012 along with the addition of microbiology, biochemistry and blood bank services. Surgical facilities were added in 2012 with a newly created surgical center. With the new center, the hospital has started providing Cesarean section deliveries aiding the safe motherhood program in the district.

\section{Preventive Care Delivery}

Possible's community health program is a partnership between Bayalpata Hospital and the network of community health workers (FCHVs) established by GoN, Ministry of Health and Population (MOHP). The program aims to improve health outcomes of people living in catchment areas of Bayalpata Hospital through provision of community-based health services by strengthening the capacity of government FCHVs, ensuring that patients, who require additional support, receive comprehensive health care. Morbidity and mortality is reduced through preventive campaign in the communities. With the initiation of Possible's community health program in 2010, the Community Health Worker Leaders (CHWLs) have been co-coordinating with the FCHVs of the respective community who have been hired by Bayalpata Hospital on a weekly basis. The CHWLs facilitate the work of the FCHVs who collect data on the various maternal and child health indicators on a weekly basis. 
By 2012, the community health network had expanded to $9 \mathrm{CHWLs}$ and $93 \mathrm{FCHVs}$ who cover a catchment area of 20554 people from 9 Village Development Committees. In its pilot phase currently, the community health program has also implemented the weekly data collection on child health indicators via mobile phones. The data generated is mapped and re-circulated back to the community health workers. There are two kinds of follow-up systems within which the patients receive follow up services. One is the general follow up where the patients encountered by the FCHVs during general surveillance are followed until the illness is cured. Follow up cases are patients who are in need of antenatal and post natal check-up, patients with HIV/AIDS or tuberculosis, malnutrition, Diabetes, rheumatic heard diseases or any other cases deemed necessary by the clinician and the Community health Department (CHD). Another is the accompaniment services where patients, who need support to access care at a higher care facility (as determined by clinical and CHD staffs, receive accompaniment services. CHD staffs accompany patients, who are referred to a higher health care facility by Bayalpata Hospital and need extra financial and logistical support. The patients are then treated at a higher-care facility in coordination with partner organizations.

\section{Rehabilitative Care Delivery}

Mental health services were established in 2011. Mental health clinic is once a week and provides counseling services by trained mental health counselors. Rehabilitative care for the ones with inability to move by supplying them with Wheel chairs and physiotherapy assistance are provided to patients who require rehabilitative care.

\section{Financing Model}

Possible utilizes a mixed model of private-public partnership financing. The MOHP, GoN provides around 35,000 USD annually for the hospital operations. The remainder of the money, approximately 750,000 USD, is collected through donor bodies (institutional, awards, competitions, and individuals). All financial and budgetary information are published in line-by-line formats. Figure 1 provides the summary of expenditures made in capital costs and operating costs prior to $7 / 17 / 2011$. All the medicinal purchases, infrastructures building contracts and the hospital supplies are made after discussions within the procurement committee meetings at Bayalpata hospital weekly or on a need basis.

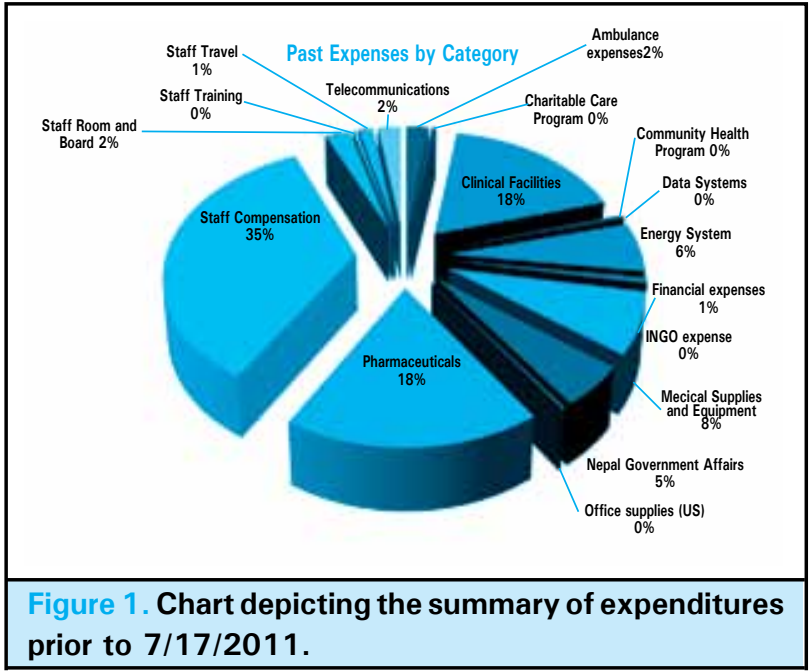

\section{Partnerships}

Possible's model of operational success thrives on partnership with Global and Nepal based partners. Building health systems in one of the poorest regions of the world requires smart and effective partnerships of all kinds. The team is always seeking strategic and reliable partnerships globally and within Nepal.

1. Funding partners: Funding for operational costs is based on partnership with Government of Nepal, Nick Simons Foundation, equity editors association and many others that believe in our work. Possible has also been collecting funds through its crowd funding partners as the Watsi and Kangu.org.

2. In-kind partners: Buddha air has been helping us with transport of our patients to higher referral centers and Abbott laboratories helping us with the laboratory facilities

3. Institution partners: To list a few, Bringham centre for surgery was partnered to upgrade the surgical facilities and Patan Academy of Health sciences as referral centers. This partnership has been instrumental for sharing of organizing policies and working together for holistic services.

\section{DISCUSSION}

\section{Access to Health Care}

Inaccessible health care is a problem in Nepal, which has prompted the GoN to implement a universal health care system. The universal health system, however, has focused more on affordability than on access. Furthermore, people have not been utilizing the services for reasons that include insufficient drug supply, travel time, staff inaccessibility, sickness, money, and facility hours. ${ }^{5}$ Government health centers tend to be less user- 
friendly and are not open $24 / 7$.

Possible addresses the inability of Achhami people to access health care. Bayalpata Hospital has been providing its services alongside District Hospital in Mangalsen, Achham. Possible's model aims to make reliable healthcare services consistently available by implementing programs with the direct participation of the community. We hope that this participation will encourage the individuals within the community to take ownership over their healthcare services. Such patient ownership should create a demand for price and quality transparency, which is a necessary first step toward developing an efficient healthcare system founded conscious of health equity.

\section{Affordability and Sustainability}

Possible was also established to address the inability of Achhami people to afford health care, as access and affordability go hand in hand. Rise in out-of-pocket costs for public and private health care services are driving many families around the world into poverty, and/or impoverishing those who are already poor into a situation known as "the medical poverty trap" which necessitates the need of an effective health system model. ${ }^{6-8}$ Possible's free health care model, similar to that advocated by Partners in Health (PIH), is about making health care and health education free to the poor. It's evident that the free health care service expansion of $\mathrm{PIH}$ is on-going despite the debates regarding sustainability and replication. ${ }^{9}$

Our experience is similar to many other groups that have found user fees discouraging. There are many groups that believe charging user fee is necessary to maintain the system. The idea of introducing user fees was tried in a public hospital in Tanzania, which saw attendance drop by $53 \%$ after the user fee was introduced. ${ }^{10}$ One study of 39 developing countries found that the introduction of user fees had increased revenues only slightly, while significantly reducing the access of lowincome people to basic social services. Other studies have shown that fees reinforce gender inequality. ${ }^{11}$ Poor people delay-seeking care until an emergency situation arises, because of financial constraints. ${ }^{6}$ The negative effects of user fees are therefore two-fold: poorer health and increased medical expenditure. Health and education are fundamental routes to development; it is counterproductive and unjust to charge user fees to those who need these services most and can afford them least. ${ }^{9}$ Additionally, transportation difficulties in the region as well as prevalent beliefs in alternative therapy services are other reasons why Possible doesn't tax on its services as this could discourage the poor in utilizing the services.
Possible has been using its unique financing mechanism to bring benefits at cost that would be fraction of the costs in the developed world. We do this by thoroughly analysing disease dynamics and prevalence to find the number needed to treat (NNT) and then stocking essential medicines required thereby keeping costs to a minimum.

\section{Utilization of services}

Since the hospital's establishment, there has been a substantial increase in service provision and utilization of services. The number of patients receiving health care services every day has been rising. Of course, free health care services might be the only reason there is an increase in demand in curative services. It is encouraging that people come for health services, even after a two day long walk, to access our quality services. In this regard, the hospital is definitely serving the Achhami community's health care needs.

It is true that with free health care service comes an increase in the demand of these services. This demand usually increases workload and unnecessary utilization of available public health services. ${ }^{12,13}$ It leads to absorption of resources allocated to free health care services by curative care resulting in budget cutback in high priority public health program. Excessive demand could lead to a lack of availability of care, causing a decrease in access to healthcare for everyone, including those who could afford to pay for it. There could be waiting lists that could prevent people from getting the care they need. Furthermore, health care providers will operate inefficiently and ultimately, the quality of care in health facilities suffers due to taxing of staff, infrastructure, drug, and decreased average consultation time.

To overcome these problems, Possible has regular meetings of the hospital management internal committee with decisions being made after open discussions with the staff. Fortunately, our health demand is not that large for waiting lists to appear. The community health workers deal with most of the minor cases. This program therefore minimizes visits for cases that can be treated or prevented early on. It is expected that majority of the cases that will present will be more major ones. Possible has been able to balance the challenge of overcoming such issues and still provide quality services by monitoring and implementation of effective measures through its data driven health care.

\section{Public-Private Partner can thrive}

Important public health conditions and diseases like malnutrition, tuberculosis, HIV and safe motherhood 
issues have been tackled in collaboration with the state and non-state partners along with hospital and community based intervention. In the year 2012, 262 babies were delivered in the hospital $145 \%$ increase from the previous year) and 34,414 patients treated ( $5 \%$ increase from the previous year). Similarly, there has been an increase of Nepali staffs by $107 \%$, which is an evidence of local capacity building. ${ }^{14}$ This health service expansion drive has been based on three main factors. The first is community-level participation and demand. The second is epidemiological data arising from community-based surveys and clinical care. The third is what interventions are available for the particular diseases in question, summarized by the number-needed-to-treat.

The main findings of this work are the critical nature of systematized care processes; the importance of the "people factor" (involvement of health professionals in decision making) an idea different from the growing role of "marketization" in health care, and fulfilling demands of the under deserved. This is done by maintaining the quality of care and building the pillars of partnership and trust. Few activities for quality improvement are listed below.

1. Clinical cases are consulted with a global volunteer clinician community via mailing services or by telemedicine services. Also clinicians volunteering for variable periods from partner organizations at the hospital are involved in case-discussions on a daily basis.

2. Monthly morbidity and mortality meetings are held along with the doctors, health assistants, nurses, administrative staffs and service and care is improved after discussions. ${ }^{15}$

3. Continuing medical education is promoted for the clinical staffs every morning with the involvement of Nepali doctors, health assistants and volunteering physicians. The learning is based on the outpatient and inpatient cases that are raised in the monthly data and evaluation meetings.

4. Possible's research wing works on various research themes that could be possible in resource -constrained settings. Further publishing of data and insights, soliciting feedback, and encouraging further discussion and analysis, can have broadbased impacts for persons in similar resourcedeprived settings that Possible does not immediately work with. Further, through continued critical analysis and peer-review; increase the exposure of Possible's work, facilitating further opportunities for future collaborations, volunteers, and funding.
5. Follow-up care in the community by Community Health workers for HIV, tuberculosis, maternal and child health, malnutrition and mental health.

\section{Conclusions}

At present the catchment area of the hospital is about $2.5+$ million. The ability to cater to this many people, given Nepal's economic and developmental state, would be considered a huge success. As all the clinical services are free to access, there is nobody who cannot afford curative services; neither would they be turned away due to pre-existing conditions. A strong community health program covering this catchment area would likely decrease patient hospital visits by preventing diseases and treating symptoms before complications develop.

There has been a constant effort to increase the services provided while maintaining their quality. Possible has been planning to extend its support and services to the local health posts in order to create a rural hub of clinical and operational excellence. There are many challenges ahead, however, for us as we expand. The first question is how to tackle affordability and sustainability? The free health care policy has many challenges, but if properly implemented and monitored, it promotes equity in health sector and contributes to achieve vision of health for all. By reviewing changes with poorer, and more vulnerable sections of society in mind, and ensuring that these groups are winners and not losers, it works for a solution to the medical poverty trap. ${ }^{16}$

\section{CONFLICT OF INTERESTS}

BB, BG, GK, AB are all paid staff of Possible, for which they receive a salary and benefits. Their salaried work is related to the work discussed in this paper; however, none of their paid-time was devoted to working on this paper specifically. RS and ZS are volunteers for the non-governmental organization, Possible; a role for which he receives no compensation. No direct funding was received for the writing of this paper. Possible, as an organization, receives financial support from individuals, foundations, and the Government of Nepal.

\section{ACKNOWLEDGEMENTS}

We would like to thank Duncan Smith Rohrberg Maru, and Dan Schwarz. 


\section{REFERENCES}

1. Hachette F. Free health care services in Nepal: Rapid assessment of the implementation and per patient expenditure, report for GTZ/GFA consulting group gmbh, health sector support programme. Kathmandu: Department of Health Services; 2009.

2. Resource Center for Primary Health Care. Briefing paper on Essential Health Care Services in Nepal. Kathmandu; Ministry of Health and Population. 2010.

3. Nyaya Health. Achham in Numbers- Nyaya Health [Online]. 2013 [Cited on 2013 October]; Available from: URL: http:/ / nyayahealth.org/Library/nyaya_brochure.pdf

4. Nyaya Health. Nyaya Vision2009[Online].2009[Cited on 2013 October]; Available from: URL: http://wiki.nyayahealth. org/w/file/52236497/Nyaya\%20Vision\%202009.pdf

5. 5. Paudel R, Upadhaya T, Pahari DP. People's Perspective on Access to Health Care Services in a Rural District of Nepal. JNMA. 2012; 52(185): 20-4.

6. Tipping G. The social impact of user fees for health care on poor households: commissioned report to the Ministry of Health. Vietnam: Ministry of Health; 2000.

7. Fu W. Health care for China's rural poor, international policy programme. Washington: World Bank; 1999.

8. Segall M, Tipping G, Lucas H, Dung TV, Tam NT, Vihn DX, et al. Health care seeking by the poor in transitional economies: The case of Vietnam. Sussex: Institute of Development Studies; 2000.
9. Partners in Health. Partners in Health: Our Mission [Online]. 2103 [Cited on 2013 October]; Available from: URL: http:/ / www.pih.org/pages/our-mission

10. Husssein AK, Mujinja PGM. Impact of user charges on government health facilities in Tanzania. East Afr Med J.1999;74(12):751-57.

11. United Nations Research Institute for Social Development (UNRISD). Visible hands-taking responsibility for social development. Geneva: UNRISD;2000.

12. Gurung G. Free Health Care Policy in Nepal: Recent Trend and Challenges .JNHRC. 2009; 7(15): 138-9.

13. RTI International. Implications of the Government of Nepal's free health care policy. Kathmandu: Health Sector Reform Support Program; 2007.

14. Nyaya Health. Nyaya Health: 2012 Annual Report [Online]. 2012 [Cited on 2013 October]; Available from: URL: http:/ / www.nyayahealth.org/wp-content/uploads/2012/07/ Nyaya-Health-Annual-Report-20121.pdf

15. 15. Schwarz D, Schwarz R, Gauchan B, Andrews J, Sharma R, Karelas G, et.al. Implementing a systems-oriented morbidity and mortality conference in remote rural Nepal for quality improvement. BMJ Qual Saf. 2011;20:1082-8.

16. 16. Whitehead M, Dahlgren G, Evans T. Equity and health sector reforms: can low-income countries escape the medical poverty trap? The Lancet. 2001;358. 